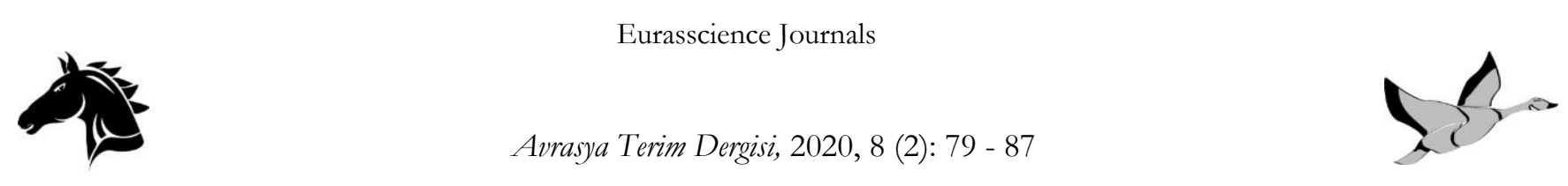

\title{
AYNI DİLİ KONUŞMAK: TRAFİK MÜHENDİSLİĞİNDE AKIM ORANI NEDİR?
}

\author{
Kemal Selçuk ÖĞ̈̈T ${ }^{1}$ \\ 1) İstanbul Teknik Üniversitesi İnşaat Fakültesi Ulaştırma Birimi, İstanbul \\ ORCID ID: 0000-0003-0844-2746, ileti; oguts@itu.edu.tr
}

Özet

Trafik mühendisliğinde, trafik akımının temel değişkenlerden olan trafik hacmi ile benzer anlamda kullanılan ve İngilizcesi "flow rate” olan terimin Türkçesi zaman içinde “akış değeri” nden hiçbir gerekçe gösterilmeden "akım oranı" olarak değiştirilerek kullanılmaya başlanmıştır. Bu değişiklik, İngilizcesi "flow ratio” olan tamamen farklı bir terimin de, Türkçe karşılığının "akım oranı” olarak kullanılmasından dolayı karışıklık yaratmaktadır. Bu yazıda, "flow rate" teriminin Türkçe'de "akım değeri” ve "akım oranı" şeklinde iki farklı kullanılış şekli tarihsel süreçte verilmekte, gerçek “akım oranı” teriminin İngilizce'deki "flow ratio” terimine karşılık geldiği günümüze kadarki yapılmış çalışmalarda gösterilmekte ve bu iki terimin sözlük anlamları irdelenmektedir. Sonuç olarak "flow rate" teriminin Türkçe karşılığı olarak yalnızca "akım değeri” teriminin kullanılması gerektiği, "akım oranı” teriminin ise yalnızca "flow ratio” teriminin Türkçe karşılığı olması gerektiği belirtilmektedir

Anahtar Kelimeler; Trafik Hacmi, Akım Oranı, Akım Değeri

\section{SPEAKING THE SAME LANGUAGE: WHAT IS THE FLOW RATE IN TRAFFIC ENGINEERING?}

\begin{abstract}
The flow rate, which is similar to traffic volume, is one of the main variables of traffic engineering. Turkish translation of this term has been changed from "akış değeri" to "akım oranı" without any explanation over years. This change causes a conflict due to the fact that "akım oranı" term is similarly used for the translation of "flow ratio" term in Turkish. In this article, the usage of two different translations of "flow rate" term, such as "akım değeri" and "akım "oranı", is given in the literature. The usage of the "akım oranı" as a translation of "flow ratio" is similarly presented and the definitions of these two terms are given. As a result, it is stated that the term "akım değeri" should be used only as the translation of "flow rate" term, and the term "akım oranı" should be only the translation of "flow ratio" term in Turkish.
\end{abstract}

Keywords; Traffic Volume, Flow Rate, Flow Ratio. 


\section{Giriş}

Dünyada kent nüfuslarının giderek artmas1, kentlerin büyümesine yol açmıs, bu büyüme sonucunda insanlar çalıştıkları yerlerden daha uzakta oturmaya başlamışlardır. Kentsel alanlarda, ev ve işyeri arasındaki uzaklığın artması, ilk çağlardan beri en gözde ulaşım türü olan yürümenin yerini taşıtların almasını gerektirmiş, 1900'lü yılların başlarında otomobilin bulunuşu ile yolculuklarda taşıt kullanımı giderek artmışıı. Bu artış sonucunda, insanlar ve taşıtlar arasındaki etkileşimin kurallara bağlanması gerekliliği ortaya çıkmış ve bu gereklilik, inşaat mühendisliğinin bir kolu olan trafik mühendisliğinin doğmasına yol açmıştır. Gerek taşıtların kendi aralarındaki, gerekse taşıt ve yayalar arasındaki etkileşimin artması bu konuda çeşitli bilimsel çalışmaların yapılmasının önünü açmış, kentlerde taşıt ve yaya sayılarının artması, bu çalışmaların hızlanarak sürmesini sağlamıştır. Trafik mühendisliği kapsamında yapilan çalışmalarda öncelikle sahadan veri toplanması gerekmekte olup bu verilerin en önemlilerinden biri, belli bir süre boyunca yoldan geçen/geçmesi öngörülen taşıt sayısıdır. Bu sayıyı belirtmek için yıllar içinde farklı tanımlamalarla farklı terimler kullanılmıştır. $\mathrm{Bu}$ terimlerden biri olan "flow rate" teriminin Türkçe karşllı̆g konusunda son yirmi yılda bir ayrışma ortaya çıkmış ve bu ayrışma giderek büyümüştür. Bu ayrışmadan, trafik mühendisliğinde çok farklı bir anlamı olan "flow ratio" teriminin de etkilendiği görülmektedir.

\section{“Flow Rate" Teriminin Doğuşu}

Trafik mühendisliği ile ilgili bilimsel çalışmaların başladığı 1900'lü yılların başlarından 1965 yılına kadar olan süreçte, bir kesitten belli bir sürede geçen taşıt sayısı, gözlem süresine bağlı olarak farklı isimlerle anılmıştır. Bir yol kesitinden belli bir zaman diliminde geçen taşıt sayıs1, "density" (Greenshield, 1935:448), "number of vehicles that could pass over a section of highway" (Greenshield, 1935:449), "volume" (Normann ve Walker, 1949:210; Ryan, 1962:102; Haight, 1963: 70) ve "flow" (Gerlough ve Capelle, 1964:vii; Haight, 1963:70) olarak adlandırlırken, bu zaman diliminin bir saat olması durumunda geçen taşıt say1s1 "density per bour" (Greenshield, 1935:449), "bourly volume" (Normann ve Walker,1949:210) ve "volume" (Gerlough ve Capelle, 1964: vii) olarak adlandırılmışır.

"Flow rate" terimi kavramsal olarak ilk kez 1962 yilinda "...the equivalent hourly rate of flow for 5 -min intervals..." (Drew ve Pinnell, 1962:1) ve "During the peak 15-min period (or in this case, during 14.4 min which represents 16 complete cycles of 54 sec each) a total of 367 vehicles entered the intersection from this one approach. This is a rate of flow of 1,529 vehicles per bour...” (Normann, 1962:56) şeklinde kullanılmıs, terimin tam tanımı ise ilk kez 1965 yilinda "Rate of flow: The hourly representation of the number of vehicles that pass over a given section of a lane or a roadway for some period less than one hour" (HRB, 1965:16) olarak yapılmıştır. Bu kaynakta, bir kesitten belli bir sürede geçen taşıt sayısina "volume" denirken, bu sürenin bir saatten kısa olması durumunda bu taşıt sayısının saatlik eşdeğerine "rate of flow" denilmiştir (HRB, 1965:16). "Rate of flow", bir saatin gözlem süresine oranlanması ile elde edilen katsayının, gözlem süresince geçen taşıt sayısı (Volume) ile çarpilması şeklinde hesaplanmaktadır. Bu nedenle "rate of flow" bir kesitten geçen, daha doğru bir deyişle geçeceği kabul edilen, saatlik taşıt sayısını göstermekte olup birimi taşıt/saat'tir.

1965 yllinda kullanılmaya başlanan "rate of flow" terimi, Karayolu Kapasite El Kitabı'nı 1994 yllındaki sürümünden (TRB, 1994:2-10) başlayarak, "flow rate" olarak kullanilmaktadır.

1965 yllından günümüze kadar pek çok yabanc1 araştırmac1 "rate of flow" ya da "flow rate" terimini kullanmış (May, 1990:54; O'Flaherty, 1997:289; Hall, 2001:2-5; Rogers, 2003:81; Roess ve ark., 2011:120) ve $\mathrm{bu}$ terim trafik mühendisliğinde s1k kullanılan terimlerden biri konumuna gelmiştir.

\section{Doğuşu}

Türkçede “Akım (Akıs) Değeri” Teriminin

"Rate of flow" teriminin ilk ortaya ç1ktı̆̆ 1960'l1 yılların başından 1975 yılına kadar Türkiye'de yayınlanan çalşsmalarda bu terime rastlanmamaktadır. $\mathrm{Bu}$ gecikmenin en önemli nedeni o dönemde bilimsel bilginin yayılma hızındaki yavaşılıtır. Internetin olmadığ ve sınırlı sayıda Türk araştırmacının ABD bağlantılarının olduğu dikkate alındığında bu gecikme son derece doğaldır. 1965-1975 yılları arasında Türkiye'de trafik mühendisliği ile ilgili yapılan çalışmalarda bir kesitten bir saatte geçen taşıt sayısını belirtmek için "saatlik trafik hacmi”" (Kutlu, 1964:12; Kutlu, 1967:149-150; Umar, 1972:64), "saatte toplam vasita" (Özdirim, 1972: 36), "saatlik trafik", "saatlik hacim" (Umar, 1972:64), "trafik hacmi” (Ünver, 1975:21), "trafik" (Zaferi, 1975:3), "saatlik debi" (Sonuç, 1975:48) terimleri kullanılmıştır.

1965 yilında ABD'de yayınlanan Karayolu Kapasite El Kitabı (HRB, 1965), 1975 yllinda Türkiye'de Karayolları Genel Müdürlüğü yayını olarak Cahit Yalgın tarafindan Türkçeye çevrilerek basılmıştır (Yalgın, 1975). $\mathrm{Bu}$ tercümenin 20. sayfasinda, "Akıs değeri (rate of flow): 
Verilen bir şerit veya platformdan bir saatten daha kusa bir süre içinde geçen taşıt sayısının saatlik olarak ifadesidir. Belli bir zaman süresi içinde geçen taşıt sayısi, 60 dakikanin o zaman süresine oran ile çarpularak genisletilmek suretiyle saatlik değer bulunur. Normal olarak sayım süresi "akus değeri" rakekamınn önüne konur. Örneğin 15 dakikada saynlan $N$ taşıt 60/15 yani 4 ile çarpularak "15-dak. akus değeri 4N taşıt" elde edilir" tanımlamas1 yer almaktadır (Yalg1n, 1975:20).

Türkiye'de ilk olarak 1975 y1linda kullanılmaya başlayan "akış değeri” teriminin araştırmacılar tarafından kullanılması uzun bir zaman almıştır. 1975 yılından sonraki çalışmalarda araştırmacılar bir kesitten bir saatte geçen taşıt sayısı için "trafik miktarı” (Özen, 1976:12; Umar ve Yayla, 1994:57), "trafik akımı" (Savran, 1977:74; Öğ̈̈t, 1998:150), “hacim” (Gedizlioğlu, 1979:108; Gedizlioğlu ve Akad, 1992:324), “saatlik trafik say1s1” (Bilge; 1980:91), "akım debisi” (Gür, 1981: 12), "saatlik trafik hacmi” (Gür, 1981:12; Tanyel ve Varlıorpak, 1998:144), "trafik hacmi” (Çelik, 1987:IV; Köprülü, 1991:20; Umar ve Yayla, 1994:57; Murat, 1998:126; Murat, 2001:186), “akım” (Varliorpak, 1987:353; Günay ve Hall, 1996:342) terimlerini kullanmışlardır.

Türkiye'de, akış değeri teriminin ortaya çıtı̆̆g 1975 y1lından 2002 y1lina kadar bu teriminin kullanımı son derece az olup, sınırlı sayıdaki çalışmada, "akım değeri" terimi, tanımlaması yapılmadan, "flow rate" teriminin Türkçe karş1lı̆̆1 olarak kullanmıştır. (Ayfer, 1977:84; Murat, 1998:127; Üçer, 2000:13; Darçın, 2001:163; Şahin, 2001:224).

Karayolları Genel Müdürlüğü tarafindan 1971 yılından yayınlanan "İngilizce Türkçe Karayollanı Teknik Sözlüğü"nde de "flow" terimi "akış, akım" olarak tercüme edilmiştir (KGM, 1971:176). Ulaştırma ve trafik mühendisliği alanlarında, "flow" teriminin Türkçe karşılığ1 olarak "akım” teriminin kullanılması son derece yerleşmiş bir konumundadır.

\section{Türkçede Akım (Akış) Değeri ve Akım} Oranı Karmaşası

2002 yilinda Nadir Yayla tarafindan yazılan Karayolu Mühendisliği kitabının 56. sayfasında: “Bir yolun nazara alinan bir kesitinden, akımm sürekli olduğu ve 1 saatten kısa bir süre içinde geçen taşıt sayısının saatlik değeri akım oramı olarak ifade edilir." cümlesi ile, "flow rate" teriminin Türkçe tercümesi olarak ilk kez "akım oranı" terimi kullanılmıştır. Bu tarihten itibaren "flow rate" teriminin Türkçe karşılığı olarak "akım değeri” ya da "akım oranı" terimleri araştırmacılar tarafindan çok kereler kullanılmıştır. 2002 yılından günümüze "akım oranı"nın, "flow rate" teriminin Türkçe karşıllı̆ı olarak kullanıldı̆̆1 çalışmalar ve bu çalışmalarda akım oranının tanımlanması şu şekildedir:

1. "Akerm oran, bir saatin belli dilimlerinde (genellikle 15 dak) yolun bir noktasından geçen araç sayısımm bir saatlik. zaman dilimine dönüstürülmesidir" (Tunç, 2003:372).

2. "Doygun akim oram \%100 etkin yeşil zamana sabip bir yaklaşım kolundan mevcut trafik ve yol şartlarinda geçen maksimum akım oran olarak tanmlanabilir. Doygun akım oran $S$ indisi ile ifade edilir ve etkin yeşil zaman için araç/sa olarak birimlendirilir" (Altun, 2003:24).

3. "Akım Oran: Belirli bir yol kesiminden veya noktasindan bir saatten daha kisa süre içinde (genellikle 15 dakika) gecen tasıt sayısmm saatlik olarak ifadesidir" (KGM, 2005:12).

4. "Hacim \& Akrm Oran: Belirli bir zaman dilimi içerisinde yolun bir kesiminden geçen arac sayısıdır. Bu belirli zaman dilimi genellikle bir saat seçilir. Akım oran ise daha kusa zamanlarda trafikte meydana gelen dalgalanmalar ve kapasiteye erişimleri gözlemlemek için kullanulır. Zirve saatte kapasiteye ulaşmayan bir kesim için, ayn saat içindeki belirli bir 15 dakikalık aralık kapasiteye ulasabilir" (Ergün ve ark., 2007:67).

5. "Akum oran (q) ise herhangi bir yol kesiminin dikkeate alinan bir kesitinden ya da bir şeridinden bir saatten daha az bir süre içinde geçen taşıt sayısının saatlik değeridir" (Başkan ve ark., 2007:161).

6. "Akus Oram ("Flow Rate") => Q (araç/sa) Bir saatte belirli bir referans noktasina göre bir şeritten geçen araç sayısıdır” (Memiş, 2008:8).

7. "Akım orani; akımın sürekli olduğu belirli bir yol kesitinden, belli bir zaman aralı̆̆ında geçen taşıt sayısıdı" (Gürsoy ve Yüksel, 2009:516).

8. "Akım oran (q); yol üzerinde belirli bir noktadan birim zamanda geçen araç sayısıdır" (Çetin 2015:23).

9. "Trafik. Akım Oranı (q) veya Hacim (trafik akımi), verilen bir süre içerisinde belirlenen bir yol kesiminden veya noktasindan geçen toplam taşıt sayısıdır" (Akpınar, 2017:23).

10. "Akus oran / flow rate: Yolun belli bir kesitinden belirli bir zaman araliğında geçen araç veya kişi sayısının zamana oranı" (UDH, 2017:10).

Yukarıda yer alan çalışmaların dişında, tanımlama yapilmadan, "flow rate" teriminin Türkçe karşılığ1 olarak "akım oranı" teriminin kullanıldı̆̆1 yayınlar da bulunmaktadır (Akgüngör, 2004:378; Başkan, 2004:62-63; Akgüngör ve ark., 2006:399; Çalışkanelli, 
2006:42; Ghasemlou, 2012:49; Güney, 2012:16; Erol, 2018:29; Demiral, 2019:5).

Benzer şekilde tanımlama yapılmadan, "flow rate" teriminin Türkçe karşılığ1 olarak "akım değeri” teriminin kullanıldı̆̆1 çalışmalar da mevcuttur (Öztürk, 2004:95; Alçelik, 2010:115; Öz, 2015:4; Korkmaz, 2019:54; Dündar, 2018:1; Turan, 2019:4).

Yukarıda sözü edilen çalışmalar bize "flow rate" teriminin Türkçe'de "akım oranı" ve "akım değeri" olarak iki farklı karşılı̆̆ının olduğunu ve araştırmacıların bu terimlerden birini tercih ettiklerini göstermektedir. Hatta bu iki terimin, "flow rate" teriminin Türkçe karş1llğ olduğu ve birbiri yerine kullanılabileceğinin belirtildiği çalışmalar olduğu gibi (Şahin, 2004: 9), bu belirtme yapılmadan "flow rate" teriminin Türkçe karşılığ1 olarak aynı çalışmanın bazı yerlerinde "akım değeri" bazı yerlerinde ise "akım oranı" terimlerinin kullanıldı ğ çalışmalar da mevcuttur (Çetin, 2015:2; Çalışkanelli ve Tanyel, 2018:8225; Karagöz, 2018:22; Erişkin, 2019:15 ve 49; Gülgeç, 2019:27 ve 40; Yiğit H.İ., 2019:26; Yiğit R.N., 2019:33-34;). Bir çalışmamım içinde, "flow rate" teriminin Türkçe karş1lı̆̆ı olarak "akım değeri” ve "akım oranı" terimlerinin kullanımının son yıllarda artması, bir sonraki bölümde açıklanacak gerekçe olmaksızın bile, bu iki terim konusunda bir karışıklığın giderek arttığını göstermektedir.

İngilizce "rate" kelimesinin Türkçe karş1lı̆g, "bir şeyin başka bir şeye oranla ölçüsü, nispet, oran, derece, mertebe, gidiş, hız, sürat, değer, kur, faiz miktarı, fiyat" (Oxford, 1977:440), "oran, nispet, aynı türden başka bir şeye göre ölçülen değer, fiyat, hız, sürat" (LongmanMetro, 1993:1241), "oran, nispet, sıklik, değer, fiyat, ücret” (Redhouse, 2005:367) olarak verilmektedir. Bu nedenle bu terim için Türkçe karşllığ1 olarak "oran" kelimesinin kullanılması ilk başta normal görülmektedir.

\section{Gerçek Akım Oranı Nedir?}

Bu noktada asıl sorun, trafik mühendisliğinde, İngilizcesi "flow ratio" olan farkl1 bir terimin mevcut olmasından kaynaklanmaktadır. "Flow ratio" kavramsal olarak 1957 yılinda ortaya çıkmakla birlikte o zaman bu terim "the ratio of flow to saturation flow" (Webster, 1957:9) şeklinde kullanılmıştır. 1957 yılından 1985 yılına kadar çeşitli araştırmacılar aynı tanımlamayı çalışmalarında kullanmışlardır (Webster ve Cobbe, 1966:46; Wagner ve ark., 1969:4; Akçelik, 1981:6; Tarnoff ve Parsonson, 1981:26). 1985 y1linda ABD'de yayinlanan Karayolu Kapasite El Kitabi'nda "flow ratio" terimi: "The flow ratio for a given approach or lane group is defined as the ratio of the actual flow rate for the approach or lane group, $v$, to saturation flow rate" (TRB, 1985:9-3) olarak tanımlanmış ve birçok araștırmaci bu tarihten başlayarak bu terimi çalışmalarında kullanmışlardır. "Flow ratio" iki akımın oranı olduğundan birimsizdir.

"Flow ratio" teriminin kavramsal olarak Türkçe'de ilk kullanılması 1977 yılında Murat Özgen Ayfer tarafından gerçekleştirilmiş, öte yandan bu terim "akım oran1" olarak tercüme edilmeyip, "akım/doygun akım oranı” olarak kullanılmıştır (Ayfer, 1977:114).

1977 yilından sonra günümüze kadar, çeşitli çalışmalarda "flow ratio" teriminin Türkçe karşılığı olarak "akım oranı" terimi tanımlanmıştır:

1. "Akum hacminin (q), doygun akuma (s) olan oramiır. Buna akım oram (y) denir. $Y=q / s$ " (Üçer, 2000:16)

2. "Akım Oranı (y) : Akım talebinin doygun akıma oramidır. $y=q / s$ " (Akdoğan ve Taçg1n, 2002:658).

3. "Flow ratio: Akem oran sinyalize kavsakta verilen bir şerit grubu için gerçek ak.rmın doymus akıma oran" (KGM, 2003:199).

4. "Yararl diğer akım parametresi de varıs akımının (hacmin) doygun akima oran seklinde hesaplanan akim oranidir. Akum oran $y$ ile ifade edilmekte ve $y=q / s$ seklinde hesaplanmaktadır" (Başkan, 2004:63).

5. " $y=$ Akerm oran $(=q / \mathrm{s}) . q=$ Tasıt $/$ saniye biriminde akım. s=Taşıt/saniye cinsinden doygun akımı" (Murat, 2006:3905).

6. " $(v / s)_{c i:} i$ inci kritik serit grubundaki akem oran" (Y1lmaz, 2006:21).

7. "Herfazıın ağırlıkl akım hacminin, doygun akımina olan oram akım oran olarak ifade edilmektedir" (Çetinkaya, 2008:12).

8. "Akerm oran (y), o ak.rm hacminin (q) doygun ak.rm (s) değerine bölümünden elde edilir” (Eraslan, 2008: 19).

9. "Yararl diğer akım parametresi de varış akıımınn (hacmin) doygun akıma oran seklinde hesaplanan akim orandır. Akım oran $y$ ile ifade edilmekte ve; $X=q / Q=q c / s g=y / u$ seklinde hesaplanmaktadır" (Dağüstü, 2010:33).

10. "...akım orani, o akırm için gerçek veya öngörülen trafik hacminin $\left(v_{i}\right)$ doygun akima $\left(s_{i}\right)$ bölünmesiyle elde edilir ve "(v/s) $)_{i}$ sseklinde gösterilir" (Akmaz, 2012:39).

11. "...akerm oran olarak tarif edilen gelen akimm doygun akıma oranıdir. $y=q / s$ ” (Alçelik, 2010:124). 
12. "Kritik akum değerinin doygun akum değerine bölünmesi ile kritik akım oranlarn $\left(Y_{i}\right)$ bulunmuş olur" (Doğan, 2014:24).

\section{3. "y: Akım oran $(y=q / s)$ " (Çakıc1, 2020:35).}

"Flow rate" ve "flow ratio" terimleri arasindaki bu karışıklık, bazı çalışmalarda aynı anda iki terimin Türkçe karşılığ1 olarak "akım oranı" teriminin kullanılmasına yol açmıştır (Başkan, 2004:63; Y1lmaz, 2006:21 Gülgeç, 2019:27 ve 50). Bu durumda, "ak1m oran1" terimi kullanıldığında, "flow rate" teriminin mi, yoksa "flow ratio" teriminin mi kastedildiği, metinin tamamını okumadan anlaşılamamaktadır.

İngilizce "ratio" kelimesinin Türkçe karşıllı̆̆1 "nispet, oran" (Oxford, 1977:441), "oran, nispet, bir miktarın içinde başka bir miktardan kaç tane olduğunu gösteren say1" (Longman-Metro, 1993:1241), “oran, nispet” (Redhouse, 2005:367) olarak verilmektedir. Öte yandan hiçbir Türkçe yayında, "flow ratio" teriminin Türkçe karşılığ1 olarak "akım oranı"ndan başka bir terim kullanılmamıştır.

\section{Sonuç ve Öneriler}

Bir şerit ya da yoldan bir saatten daha kısa bir süre içinde geçen taşıt sayısının saatlik eşdeğeri olan "flow rate" teriminin birimi taşıt/saat'tir. Gerek tanımına gerekse birimine bakıldığında bu terimin bir "oran" olmadığ1 anlaşılmaktadır. Tarihsel süreç incelendiğinde, "flow rate" teriminin Türkçe'ye ilk olarak doğru bir şekilde tercüme edildiğini (akış değeri), ancak zaman içinde terimin anlamı tam irdelenmeden, yalnızca "rate" kelimesinin Türkçe karşılığına dikkat edilerek "akım oranı" şeklinde tercüme edildiği anlaşılmaktadır. Ayrıca bu hatalı tercüme sirasinda, bu tercümeden çok önce ortaya çıkan "flow ratio" teriminin varlığ1 ve bu terimin ne şekilde Türkçe'ye tercüme edileceğinin de gözden kaçtı̆̆1 görülmektedir.

Öte yandan, 1şıklı bir kavşakta geçen akımın doymuş akıma oranı olarak tanımlanan ve birimsiz olan "flow ratio" terimi, tam anlamiyla bir orandir, bu nedenle de birimsizdir. Iş1klı bir kavşakta, her şerit grubu için hem "flow rate" hem de "flow ratio" değerleri hesaplanmaktadır. Bu nedenle iki terim için farklı Türkçe karşılıkların kullanılması zorunludur.

Yukarıda açıklanan yaklaşımlar doğrultusunda, bundan sonra "flow rate" teriminin Türkçe karşıllı̆̆1 olarak yalnızca "akım değeri”" teriminin kullanılması, "akım oranı" teriminin ise yalnızca "flow ratio" teriminin Türkçe karşılığı olarak kalması, bu iki terimin birbirine karışmaması açısından zorunludur. Böylelikle bu iki terim arasinda son yillarda giderek artan karmaşıklığın önlenmesi mümkün olacaktır.

\section{Kaynaklar}

Akçelik, R., 1981. Traffic Signals: Capacity and Timing Analysis, Australian Road Reseach Board, Research Report AAR No.123: 108 sayfa.

Akdoğan E., ve Taçgin E., 2002. Zeki Bir Trafik Kontrolü Denemesi: Bir Kavşağın Kontrolü için Geliştirilen Prototip Uzman Sistem, Otomatik. Kontrol Türk Milli Komitesi Otomatik Kontrol Ulusal Toplantist: 655-664.

Akgüngör, A., P., 2004. Sinyalize Kavşaklarda Gecikme Tahmininin Matematiksel Modellenmesi I: Farklı Çözümleme Süreleri İçin Zamana Bağlı Yeni Bir Gecikme Modeli. Teknoloji Dergisi, 7 (3): 369-379.

Akgüngör, A., P., Demirel, A., Doğan, E., Gürbüz, T., 2006. Sağa Dönen Taşıt Trafiğinin Anayol Üzerinde Sebep Olduğu Gecikme ve Yakıt Tüketimi İçin Yeni Bir Model Önerisi. Süleyman Demirel Üniversitesi Fen Bilimleri Enstitüsü Dergisi, 10(3): 398-403.

Akmaz, M., M., 2012. Konya’nn Önemli Sinyalize Kavsaklarmm Bilgisayar Progrem ile Incelenmesi. Yüksek Lisans Tezi, Selçuk Üniversitesi, 103 sayfa.

Akpınar, M., V., 2017. Örneklerle Karayolu Tasarmı. Birsen Yayınevi, 280 sayfa.

Alçelik, N., 2010. Kentiçi Sinyalize Dönel Kavşaklarn Kapasite Açısından Karşılassturılması Ümraniye İlçesi Örneğinin Incelenmesi. Yüksek Lisans Tezi, Bahçeşehir Üniversitesi, 319 sayfa.

Altun, I., 2003. Sinyalize Kavşaklarda Trafik Akım Etkilessimleri. Yüksek Lisans Tezi, Dokuz Eylül Üniversitesi, 124 sayfa.

Ayfer, M., Ö., 1977. Trafik Sinyalizasyonu. TC Bayındırlık Bakanlı̆̆1, Karayolları Genel Müdürlüğü, Yayın No: 226, 184 sayfa.

Başkan, Ö., 2004. İole Sinyalize Kavşaklardaki Ortalama Taşıt Gecikmelerinin Yapay Sinir Ağlar ile Modellenmesi. Yüksek Lisans Tezi, Pamukkale Üniversitesi, 120 sayfa.

Başkan, Ö., Ceylan, H., Haldenbilen, S., Ceylan, H., 2007. Kentiçi Yollarda Hiz Yoğunluk Kapasite İlişkisi ve Kapasite Kullanım Oranının 
Belirlenmesi. 5. Kentsel Altyapı Ulusal Semposyumu, Antakya: 159-169

Bilge, F, 1980. Yol ve Yol Projesi Ders Notlar. Sakarya Devlet Mühendislik ve Mimarlık Akademisi Ders Notlar1 No:15, 317 sayfa.

Çakıc1, Z., 2020. Sinyalize Kavşaklar için Optimizasyon Tabanle Trafik Yönetim Modeli. Pamukkale Üniversitesi, 173 sayfa.

Çalışkanelli, S., P., 2006. Yakın Mesafeli Sinyalize Kavşaklarla Kontrolsüz Kavşak Etkileşimi. Yüksek Lisans Tezi, Dokuz Eylül Üniversitesi, 91 sayfa.

Çalışkanelli, S., P., ve Tanyel, S., 2018. Sinyalize Kavşaklarda Doygun Akım Değerinin İrdelenmesi. İmo Teknik Dergi:8225-8248..

Çelik, F., 1987. Denetimsiz Eşdürey Kavsak Sisteminin Simülasyonu ve Taşıt Gecikmelerinin Formüle Edilmesi. Doktora Tezi , İstanbul Teknik Üniversitesi, 114 sayfa.

Çetin, M., 2015. Sinyalize Kavşaklarda Doygun Akım Oranmm Belirlenmesinde Yeni Bir Yaklassm. Doktora Tezi, Pamukkale Üniversitesi, 118 sayfa.

Çetinkaya, G., 2008. Işılkl Kavşaklarda Değģşik Hesaplama Yöntemlerinin Karşılaștirlması. Yüksek Lisans Tezi, İstanbul Teknik Üniversitesi, 80 sayfa.

Dağüstü, H., Ş., 2010. Trafik Yönetiminde Kavşak Trafiğinin Kontrolü için Bir Sinyal Zamanlama Modeli. Yüksek Lisans Tezi, Yıldız Teknik Üniversitesi, 137 sayfa.

Darçın A., 2001. Sinyalli Kavşaklardaki Yaya Geçitlerinde Yaya-Motorlu Taşıt Etkileşiminin Modellenmesi. 5. Ulaștrma Kongresi Bildiriler Kitabr, TMMOB İnşaat Mühendisleri Odası, İstanbul: 159-170.

Demiral, A., C., 2019. Antalya İli Muratpaşa İlçesi'nde Sinyalize Kavşak Analizi Örmek Calsșması. Yüksek Lisans Tezi, Akdeniz Üniversitesi, 90 sayfa.

Doğan, E., 2014. Optimize Edilmis Bulanı. Mantık Yöntemi Ile İole Sinyalize Kavsak Kontrolï. Doktora Tezi, Kurrkkale Üniversitesi, 159 sayfa.

Drew, D., R., and Pinnell, C., 1962. A Study of Peaking Characteristics of Signalized Urban Intersections as Related to Capacity and Design. Traffic Characteristics and Intersection Capacities II. Intersection Capacity, Highway Research Board Bulletin 352, National Academy of Sciences Publication 1047: 1-55.
Dündar, S., 2018. Istanbulda'ki Işılkh Kavşaklarda Doygun Akem Değerini Etkileyen Geometrik Değiskenlerin Incelenmesi. Doktora Tezi, İstanbul Teknik Üniversitesi, 154 sayfa.

Eraslan, O., 2008. Isslkh Kavsaklarda Amerika ve Avustralya Yöntemleri ile Gecikme Analizi ve Örnek Bir Kavsake Cözümü. Yüksek Lisans Tezi, İstanbul Teknik Üniversitesi, 95 sayfa.

Ergün, G., Gün, F., Çalışkan, B., 2007. Link-Kapasite Fonksiyonlarmm Geliștirilmesi. İstanbul Metropoliten Planlama ve Kentsel Tasarım Merkezi, 80 sayfa.

Erişkin, E., 2019. Sinyalize Kavşaklarda Gecikme Modelleri. Doktora Tezi, Süleyman Demirel Üniversitesi, 71 sayfa.

Erol, D., 2018. Kentiçi Ișıklı ve Dönel Kavșak Uygulamalarmin Performans Kriterlerine Etkisi: Deniəli Örmeği. Yüksek Lisans Tezi, Pamukkale Üniversitesi, 89 sayfa.

Ghasemlou, K., 2012. Otobüslerin Sinyalize Kavsaklarn Kapasitesine Etkilerinin Modellenmesi. Yüksek Lisnas Tezi, Dokuz Eylül Üniversitesi, 113 sayfa.

Gedizlioğlu, E., 1979. Denetimsiz. Kavşaklarda Yanyol Sürücülerinin Davranıslarna Göre Pratik Kapasite Saptanması İcin Bir Yöntem. Doktora Tezi, İstanbul Teknik Üniversitesi, 128 sayfa.

Gedizlioğlu, E., ve Akad, M., 1992. Kentiçi Şişeboynu Kesimlerde Kapasite Kullanımı: Boğaziçi Köprüsü Örneği. İstanbul 2. Kentiçi Ulaşım Kongresi Bildiriler Kitabı, TMMOB İnşaat Mühendisleri Odası, İstanbul: $323-338$

Gerlough D., L, and Capelle, D., G., 1964. An Introduction to Traffic Flow Theory. Highway Research Board, Special Report 79: 233 sayfa.

Greenshield, B., D., 1935. A Study of Traffic Capacity. Proceeding, 14. Annual Meeting Highway Research Board: 448-477.

Gülgeç, Y., N., 2019. Sinyalize Kavsakelarda Trafike Akım Etkileşimleri ve Bulanı Mantık ile Değerlendirilmesi Bahkesir Örneği. Yüksek Lisans Tezi, Balıkesir Üniversitesi, 133 sayfa.

Günay, B. ve Hall, M., G., H., 1996. Trafik Tikanıklıklarına Çözüm Olarak Elektronik Yol Yönlendirme Sisemlerinin Kullanımı ve İstanbul 
Boğaz Geçiși Örneği. Birinci Ulusal Ulașım Sempozyumu: 337-348.

Güney, E., 2012. Farklı Hava Koşullarnda Trafiik. HızAkrm-Yoğunluk Modelleri. Yüksek Lisans Tezi, Kırıkkale Üniversitesi, 105 sayfa.

Gür, G., 1981. Tatil ve Geži Trafig̈i Bilesseni Yüksek Trafik Akımlarmm Deterministik. Analizi. Ege Üniversitesi, 135 sayfa.

Gürsoy, M. ve Yüksel, H., 2009. Kentiçi Trafik Kazalarının Çevre ve Ulaşım Koşullarına Bağlı Olarak İncelenmesi. İzmir Ulaşım Semposyumu: 594602.

Haight F., A., 1963. Mathematical Theories of Traffic Flow. Volume 7, Academic Press Inc. 255 sayfa.

Hall, F., L., 2001. Traffic Stream Charactersitics. Revised Traffic Flow Theory A State-of-the-Art Report, Transportation Research Board: 367 sayfa.

HRB, 1965. Higway Capacity Manual 1965. Highway Research Board, Special Report 87 National Academy of Sciences Publication 1328, 426 sayfa.

Karagöz, G., T., 2018. Kent $\dot{I}_{c ̧} i$ Sinyalize Eşdüzey Kavsakelarda Sinyalizasyon Sisteminin Modellenmesi ile Trafik Akısımmn İyilestirilmesi. Yüksek Lisans Tezi, Eskişehir Osmangazi Üniversitesi, 80 sayfa.

KGM, 1971. Ingilizce Türkse Karayollar Teknik Sözliügü. Karayolları Genel Müdürlüğü Bayındırlık Bakanllğı, 527 sayfa.

KGM, 2003. İngilizce-Türkçe, Karayollar Teknik Sözliügü. T.C. Bayındırlık ve İskan Bakanlı̆ı Karayolları Genel Müdürlüğü.

KGM, 2005. Karayolu Tasarm El Kitabı. Karayollar1 Genel Müdürlüğü, 297 sayfa.

Korkmaz, E., 2019. İzole Sinyalize Kavşaklarda Yapay Zeka Teknikleri ile Trafik sinyal Kontrolü ve Optimizasyonu. Doktora Tezi, Kırıkkale Üniversitesi, 133 sayfa.

Köprülü, L., 1991. Bağdat Caddesi'nde Trafike Akum Incelemesi. Yüksek Lisans Tezi, İstanbul Teknik Üniversitesi, 111 sayfa.

Kutlu, K., 1964. Trafik Etüdleri. İTÜ Kütüphanesi Say1 568,371 sayfa.

Kutlu, K., 1967. Trafik Tekniği. İTÜ Kütüphanesi Say1 680.
Longman-Metro, 1993. Ingiližce, Türkçe Sözlük, 1760 sayfa.

May, A., D., 1990. Traffic Flow Fundamentals. Prentice Hall Inc, 464 sayfa.

Memiş, K., 2008. Trafik Akışkanliğgnn Doğrusal Simflayzcilar Vasitasylla Belirlenmesi. Yüksek Lisans Tezi, Ege Üniversitesi, 106 sayfa..

Murat, Y., Ş., 1998. Denizli Şehiriçi Kavşaklarındaki Trafik Akımlarının İncelenmesi. 4. Ulastırma Kongresi Bildiriler Kitabı I, TMMOB İnşaat Mühendisleri Odas1, Denizli: 121-133.

Murat, Y., Ş., 2001. Sabit Zamanlı Sinyalizasyon Sistemlerinin Başarımının Benzetim Programları ile Değerlendirilmesi. 5. Ulaştırma Kongresi Bildiriler Kitabı, TMMOB İnşaat Mühendisleri Odası, İstanbul: 181-190.

Murat, Y., Ş., 2006. Sinyalize Kavşaklardaki Taşıt Gecikmelerinin Bulanık Mantık ile Modellenmesi. IMO Teknik Dergi, Yaz1 258: 3905.

Normann, O., K., and Walker, W., P., 1949. Highway Capacity: Practical Applications of Research, Public Roads A Journal of Highway Research, 25 (10): 201-278.

Normann, O., K., 1962. A Study of Peaking Characteristics of Signalized Urban Intersections as Related to Capacity and Design. Traffic Characteristics and Intersection Capacities II. Intersection Capacity, Highway Research Board Bulletin 352, National Academy of Sciences Publication 1047: 55-99.

O'Flaherty, C., A., 1997. Transport Planning and Traffic Engineering. Butterworth-Heinemann Elsevier, 561 sayfa..

Oxford, 1977. The Oxford English-Turkish Dictionary.

Öğüt, K., S., 1998. Trafik Akımlarının Spektral Analiz Yöntemi ile Modellenmesi. 4. Ulasttrma Kongresi Bildiriler Kitabı I, TMMOB İnşaat Mühendisleri Odas1, Denizli: 147-155.

Öz, L., 2015. İstanbul Kentiçi Cevre Yolu Trafik Verilerinin Analiži. Yüksek Lisans Tezi, Bahçeşehir Üniversitesi, 71 sayfa.

Özdirim, M., 1972. Türkiye'de Trafik Sinyalizasyonunun Formüle Edilmesi. Doktora Tezi, İstanbul Teknik Üniversitesi, 64 sayfa. 
Özen, S., 1976. İstanbul Sehiriçi Anayollarinda Seyahat Hızın Etkileyen Faktörler ve Seyahat Hiz ile Trafik Miktar Arasındaki Bağıntı. Diploma Çalışması, 90 sayfa.

Öztürk, E., A, 2004. Sinyalize Kavşaklarda Periyot Süresinin Modellenmesi: Ankara Örnĕgi. Doktora Tezi, Gazi Üniversitesi.

Redhouse, 2005. Ingilizce-Türkese, Türkese-İngiliz̧ce Yeni El Sözlüğ̈. On Sekizinci Bask1, 702 sayfa.

Roess, R., P., Prassas, E., S., \& McShane, W., R., 2011. Traffic Engineering Fourth Edition. Pearson Press, 744 sayfa.

Rogers, M., 2003. Highway Engineering. Blackwell Publishing, 294 sayfa.

Ryan, D., P, 1962. A Study of Peaking Characteristics of Signalized Urban Intersections as Related to Capacity and Design. Traffic Characteristics and Intersection Capacities II. Intersection Capacity, Highway Research Board Bulletin 352, National Academy of Sciences Publication 1047: 100-114.

Savran, O., A., 1977. Kent Yol Ağ̀ Tipleri ve Konunun Istanbul Açısından Incelenmesi Baz̨ Öneriler. Ulaştırma Dalı Diploma Tezi, MMLS, 93 sayfa.

Sonuç, T., 1975. Karayolu Tekniği Cilt 1. Sermet Matbaas1, 330 sayfa.

Şahin, İ., 2001. İstanbul Boğaziçi Köprüsü Bağlantı Yollarında Kapasite Kullanım Düzeyinin Araştırılmas1. 5. Ulaştırma Kongresi Bildiriler Kitabı, TMMOB İnşaat Mühendisleri Odas1, İstanbul: 223-230.

Şahin, İ., 2004. Uzun Otoyol Kuyruklarmm Incelenmesi ve Iyileștirme Stratejilerinin Arasttrilması: Tübitak Proje No: İÇTAG-I920., 152 sayfa.

Tanyel, S., ve Varlıorpak, C.., 1998. Yeni Tip Dönel Kavşak Uygulama Örnekleri. 4. Ulaştırma Kongresi Bildiriler Kitabı I, TMMOB İnşaat Mühendisleri Odas1, Denizli: 135-146.

Tarnoff, P., J., \& Parsonson, P., S., 1981. Selecting Traffic Signal Control At Individual Intersections. National Cooperative Highway Reseach Program Report No: 233, 133 sayfa..

TRB, 1985. Highway Capacity Manual. Special Report 209, Transportation Reseach Board, 459 sayfa..
TRB, 1994. Highway Capacity Manual. Special Report 209, Transportation Reseach Board, Third Edition.

Tunç, A., 2003. Trafik Mühendisliği ve Uygulamalar. 1. Baskı, Asil Yayın Dağıtım, 790 sayfa.

Turan, C., 2019. Sinyalize Dönel Kavşaklarn Trafik Mikrosimülasyon Yönetimi ile Modellenmesi ve Iyilestirilmesi Önerilerinin Analizi. Yüksek Lisnas Tezi, İstanbul Üniversitesi Cerrahpaşa Lisansüstü Eğitim Enstitüsü, 164 sayfa.

UDH, 2017. Akıllı Ulaşım Sistemleri Terimleri Sözlügü̈. TC, Ulaştırma Denizcilik ve Haberleşme Bakanlığı, 1. Bask1, 134 sayfa.

Umar, F., 1972. Yol İnşaatı Dersleri. İTÜ İnşaat Fakültesi Ders Notları, İstanbul Teknik Üniversitesi, İnşaat Fakültesi Matbaası Say1: 987, 458 sayfa..

Umar, F., ve Yayla, N., 1994. Yol Inssaatı. 4. Bask1, İstanbul Teknik Üniversitesi Rektörlüğü, Say1 1541, 287 sayfa.

Üçer, F., 2000. Balıkesir İlinde Önemli Kavşaklarm Kapasite Yönünden Değerlendirilmesi. Yüksek Lisans Tezi, Balıkesir Üniversitesi, 260 sayfa.

Ünver, H., 1975. Sinyalize Kavsaklarm Projelendirilmesinde Kapasite Analizi Tekniği. Yeterlik Çalışması, İstanbul Devlet Mühendislik ve Mimarlık Akademisi İnşaat Bölümü, 48 sayfa.

Varlıorpak, C.., 1987. Yaklaşan Trafik Akımlarının Nümerik Analizi. Türkiye İşaat Mühendisliği 9. Teknik Kongresi: 345-359.

Wagner, F., A., Gerlough, D., L., \& Barnes, F., C., 1969. Improved Criteria for Traffic Signal Systems on Urban Arterials. National Cooperative Highway Reseach Program Report No:73, 55 sayfa.

Webster, F., V., 1957. Traffic Signal Setting. Road Research Technical Paper No:39, Department of Scientific and Industrial Research London, England, 43 sayfa.

Webster, F., V., and Cobbe, B., M., 1966. Traffic Signals. Road Research Laboratory, Road Research Technical Paper No.56, 111 sayfa.

Yalgın, C., 1975. Yollarn Kapasitesi: Bayındırlık Bakanlı̆̆1 Karayolları Genel Müdürlüğü, Yayın No 219, 249 sayfa. 
Yayla, N., 2002. Karayolu Mühendislï̆i. Birsen Yayınevi, 285 sayfa.

Y1lmaz, E., 2006. Karayolu Trafik Simülasyonu. Yüksek Lisans Tezi, Karadeniz Teknik Üniversitesi, 76 sayfa.

Yiğit H., İ., 2019. Koordine Sinyalize Kavşaklarda Gecikme Modellemesi:Ulus Bulvar Örneği, Deniə̧i: Yüksek Lisans Tezi, Pamukkale Üniversitesi, 89 sayfa.
Yiğit, R., N., 2019. Kısa Zamanlı Trafike Tabmini ile Devre Süresi Optimizasyonu ve Gecikme Analizi. Yüksek Lisans Tezi, Pamukkale Üniversitesi, 137 sayfa.

Zaferi, C., 1975. İstanbul Cevre Yolu Halic Köprüsü Trafiği. Bitirme Ödevi, İstanbul Teknik Üniversitesi Yollar ve Trafik Kürsüsü, 152 sayfa. 